\title{
Study on lowering the percolation threshold of carbon nanotube-filled conductive polypropylene composites
}

\author{
Seung Bin Park ${ }^{1}$, Moo Sung Lee ${ }^{2}$ and Min Park ${ }^{3, \text {, }}$ \\ ${ }^{1}$ Lotte Chemical Research Center, Daejeon 305-726, Korea \\ ${ }^{2}$ School of Applied Chemical Engineering, Chonnam National University, Gwangju 500-757, Korea \\ ${ }^{3}$ Soft Innovative Materials Research Center, Korea Institute of Science and Technology, Wanju 565-905, Korea
}

\section{Article Info \\ Received 2 February 2014 \\ Accepted 28 February 2014}

*Corresponding Author

E-mail: minpark@kist.re.kr

Tel: $+82-63-219-8120$

\section{Open Access}

DOI: http://dx.doi.org/

10.5714/CL.2014.15.2.117

This is an Open Access article distributed under the terms of the Creative Commons Attribution Non-Commercial License (http://creativecommons.org/licenses/ by-nc/3.0/) which permits unrestricted non-commercial use, distribution, and reproduction in any medium, provided the original work is properly cited.

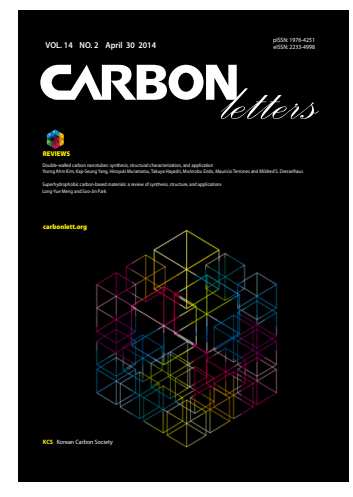

http://carbonlett.org

pISSN: $1976-4251$

elSSN: 2233-4998

Copyright $\odot$ Korean Carbon Society

\begin{abstract}
Conductive polymer composites (CPCs) consist of a polymeric matrix and a conductive filler, for example, carbon black, carbon fibers, graphite or carbon nanotubes (CNTs). The critical amount of the electrically conductive filler necessary to build up a continuous conductive network, and accordingly, to make the material conductive; is referred to as the percolation threshold. From technical and economical viewpoints, it is desirable to decrease the conductive-filler percolation-threshold as much as possible. In this study, we investigated the effect of polymer/conductive-filler interactions, as well as the processing and morphological development of low-percolation-threshold $(\Phi c)$ conductive-polymer composites. The aim of the study was to produce conductive composites containing less multi-walled CNTs (MWCNTs) than required for pure polypropylene (PP) through two approaches: one using various mixing methods and the other using immiscible polymer blends. Variants of the conductive PP composite filled with MWCNT was prepared by dry mixing, melt mixing, mechanofusion, and compression molding. The percolation threshold $(\Phi c)$ of the MWCNT-PP composites was most successfully lowered using the mechanofusion process than with any other mixing method (2-5 wt \%). The mechanofusion process was found to enhance formation of a percolation network structure, and to ensure a more uniform state of dispersion in the CPCs. The immiscible-polymer blends were prepared by melt mixing (internal mixer) poly(vinylidene fluoride) (PVDF, PP/PVDF, volume ratio 1:1) filled with MWCNT.
\end{abstract}

Key words: conductive polymer composite, multi-walled carbon nanotube, polypropylene

\section{Introduction}

Conductive polymer composite (CPCs) are obtained by blending conductive fillers such as carbon black, carbon fibers, graphite and carbon nanotubes [1-5]. Table 1 shows the properties of various conductive carbonaceous fillers used to make CPCs [6]. In recent years, CPCs have been widely used in positive temperature coefficient materials, electrostatic dissipation, and electromagnetic interference (EMI) shielding due to their good electrical conductivity, light weight, and corrosion resistance. Fig. 1 shows that the major applications for electrically conductive polymers or composites depend upon the magnitude of the electrical conductivity. A conductive composite can be used as an antistatic material if its surface electrical conductivity is higher than $10^{-12} \mathrm{~S} / \mathrm{cm}$. When the surface electrical conductivity of a composite is higher than $10^{-10} \mathrm{~S} / \mathrm{cm}$, it can be used for electrostatic discharge. A composite can be used as shielding for electromagnetic or radio-frequency interference if the surface electrical conductivity is higher than $10^{-6} \mathrm{~S} / \mathrm{cm}$. Providing the amount of conductive filler required to achieve a sufficient level of electrical conductivity often leads to processing difficulties and brittle composites $[7,8]$. From technical and economical viewpoints, it is desirable to decrease the conductive-filler percolation-threshold as much as possible. 
Table 1. Properties of various conductive carbonaceous fillers [6]

\begin{tabular}{cccc} 
Property & $\begin{array}{c}\text { Carbon } \\
\text { nanotube }\end{array}$ & $\begin{array}{c}\text { Carbon } \\
\text { black }\end{array}$ & $\begin{array}{c}\text { Carbon } \\
\text { fiber }\end{array}$ \\
\hline $\begin{array}{c}\text { Loading requirements } \\
\text { Ability to adjust } \\
\text { conductivity }\end{array}$ & $2-5 \%$ & $25-35 \%$ & $15-20 \%$ \\
$\begin{array}{c}\text { Ease of distribution in } \\
\text { polymer }\end{array}$ & Problematic & Acceptable & Good \\
$\begin{array}{c}\text { Part performance } \\
\text { Sloughing }\end{array}$ & Little change & Degraded & Variable \\
Surface finish & Good & Poor & Acceptable \\
Ease of pigmentation & Good & Unceptable & Acceptable \\
Cost of filler & $\$ 20$ & $\$ 1-2$ & Good \\
Cost of finished polymer & $\$ 15-20$ & $\$ 2-4$ & Acceptable \\
Performance/cost & Very high & low & high \\
\hline
\end{tabular}

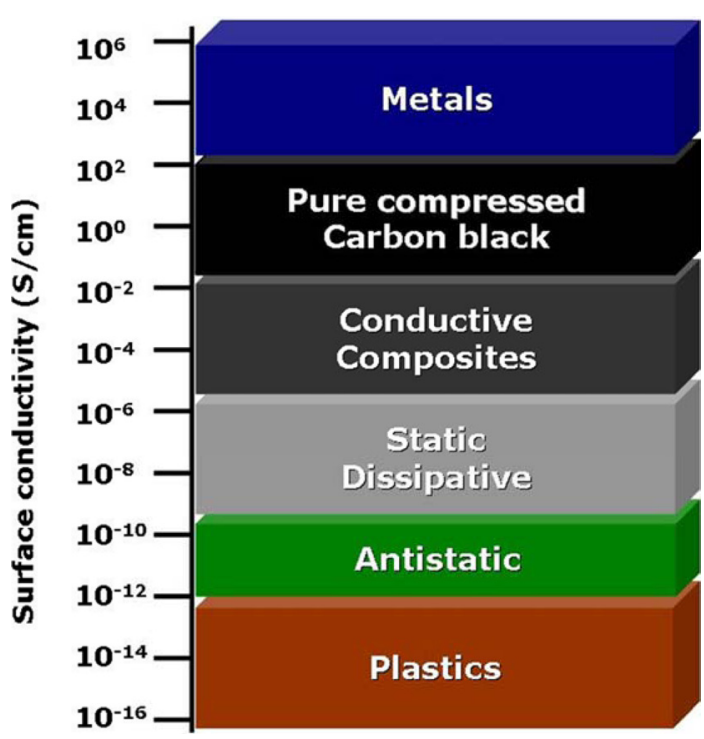

Fig. 1. Applications for electrically-conductive polymers.

In order to get conductive materials at very low loading levels, workers in several studies showed that introducing carbon nanotubes (CNTs) into polymeric matrixes was very effective [9]. This was due to its excellent electrical properties in combination with its very high aspect-ratio (as high as 1000 for multiwalled CNT [MWCNT]), which enabled percolation of the conductive fillers at low concentrations [10,11]. There are several ways to decrease the percolation threshold of CNT in polymers, mainly based on the use of additives, the optimization of processing conditions, and managing the size distribution [12-14].

Traditional polymer processing methods, including extrusion and injection molding, can be utilized. In this study, we focused on achieving a low percolation threshold for conductive CNTpolymer composites with two different approaches: an immiscible polymer blend and a mechanofusion technique. Immiscible polymer blends involve the concept of 'double percolation', in which the percolation of the CNT occurs in a phase that is also continuous, thus creating a second percolation. In other words, the blend showed that the selective localization of CNTs in one polymer phase from a co-continuous blend, could reduce the amount of CNT needed for percolation.

Modern materials technologies increasingly call for ultra-fine particles to be handled and modified in a targeted manner. Customized physicochemical properties of individual particles form the basis for highly developed functionality of raw materials. In order to influence the function of the particles, it is possible to combine the material properties of different components with one another. This is accomplished by mechanically "fusing" individual particles which have different properties (e.g., hardness, chemical resistance, conductivity, and color). With reference to the process described here, we have termed this fusion of individual particles "mechanofusion." Put simply, this is a process during which powders and powder mixtures are stressed by mechanical energy introduced from outside. This leads in the first instance to intensive de-agglomeration and blending, then to a convergence of the particles being combined with subsequent adhesion, and finally, to fusion.

In this study, two different approaches (immiscible polymer blend and mechanofusion process) were used to make CPCs with a low concentration of conductive filler.

\section{Experimental Procedures}

\subsection{Materials}

Polypropylene (PP) has been widely used as a polymer matrix to fabricate electrical conductive composites. Powdery isotactic PP (Samsung Total Petrochemicals Co., Korea) in the form of almost spherical particles (200-500 $\mu \mathrm{m}$ average particle size) and powdery poly(vinylidene fluoride) (PVDF, Kynar 721 grade, Akema Inc.) with an average particle size of $1 \mu \mathrm{m}$, were used as the polymer matrix. As conductive filler, MWCNT (Nanotube Research Laboratory, Korea University, Korea) were synthesized by thermal-chemical vapor-deposition of ethylene gas at $700^{\circ} \mathrm{C}$ with $\mathrm{Fe}-\mathrm{Mo} / \mathrm{Al}_{2} \mathrm{O}_{3}$ as catalysts. Purity of the MWCNT, as received, was $95 \%$. Scanning electron microscopy (SEM) examination revealed that the MWCNTs were entangled and partly conglomerated. The average diameter of the MWCNT ranged from 10 to $20 \mathrm{~nm}$ while their lengths were $10-50 \mu \mathrm{m}$.

\subsection{Composite preparation}

\subsubsection{MWCNT acid-treatment}

To eliminate impurities in the MWCNT, $20 \mathrm{mg}$ of MWCNT were poured into a $500 \mathrm{~mL}$ beaker containing $100 \mathrm{~mL}$ of aqua regia (a mixture of $98 \%$ sulfuric acid and $68 \%$ nitric acid, $3: 1$ by volume) at $25^{\circ} \mathrm{C}$ for $2 \mathrm{~h}$. After being washed with distilled water until a neutral $\mathrm{pH}$ was maintained, and then freeze dried for $24 \mathrm{~h}$, the acid-treated MWCNTs were obtained. These acid-treated MWCNTs were used to prepare all the conductive-polymer composite samples. 


\subsubsection{Mixing techniques}

1) Conventional dry mixing. Each MWCNT and powdery PP were dry-mixed in a high-speed mixer for $2 \mathrm{~min}$.

2) Immiscible polymer blend. The following procedure was followed in order to determine the thermodynamically-driven MWCNT migration in polymer blends during melt blending. First, PP, PVDF (volume ratio 1:1), and MWCNT were mixed in an internal mixer at the same time at $180^{\circ} \mathrm{C}$ for $10 \mathrm{~min}$, the screw rotating speed being $60 \mathrm{rpm}$. Next, PP (or PVDF) and MWCNT were mixed in an internal mixer at $180^{\circ} \mathrm{C}$, with a screw-rotating speed $60 \mathrm{rpm}$ for $4 \mathrm{~min}$. Then PVDF (or PP) was quickly added and mixed for $6 \mathrm{~min}$. The final blends were compression-molded into $1 \mathrm{~mm}$ thick sheets using a tetrahedron at $180^{\circ} \mathrm{C}$.

A polymer blend of PP with PVDF (volume ratio $=1: 1$ ) containing 1-20 wt $\%$ MWCNT were prepared by melt-mixing in an internal mixer. The influence of the blending procedure on the electrical properties of the blends was investigated using three modes of ingredient incorporation for addition of MWCNT to the polymer blend.

3) Mechanofusion. The MWCNT/PP composite samples were prepared by mechanofusion according to the dry-particle coating method. The MWCNT and PP powders were pre-mixed using a high-speed mixer for $2 \mathrm{~min}$, and then the mixture was treated with a mechanofusion system (AMS-mini, Hosokawa Micrometer Corp.) at a chamber-rotation speed of $2500 \mathrm{rpm}$ for $15 \mathrm{~min}$. The gap distance between the inner chamber wall and an arm-head was set to $1 \mathrm{~mm}$. Particles were pressed onto the inner wall by centrifugal, compression, and shearing forces.

All the final composites were compression-molded using a tetrahedron at $180^{\circ} \mathrm{C}$, under a $3 \mathrm{klbf}$ pressure, into sheets about $1 \mathrm{~mm}$ thick.

\subsection{Measurements}

\subsubsection{Microscopy}

The morphology of the polymer blends and distribution, as well as the dispersion state of the MWCNT in the polymer matrix, was observed by optical microscopy (OM) and SEM operated at high voltage $(10 \mathrm{KV})$ after Pt coating. The composite samples for microscopy were prepared by microtome at room temperature.

\subsubsection{Electrical conductivity}

The CPC samples were of length $70 \mathrm{~mm}$, width $20 \mathrm{~mm}$, and thickness $\sim 1 \mathrm{~mm}$. The electrical conductivity of the composite was measured through the vertical thickness of the composite sheets by the standard, four-point-probe method. A DC precision power source (Keithley, Model 6280) and nano-voltmeter (Keithley, Model 2182A) were used for all measurements. An electrical current of $1 \mathrm{~mA}$ was maintained in all measurements. Values of the volume electrical conductivity, $\sigma$, were obtained by simply inverting the corresponding values of the resistivity as follows:

$$
\sigma=\rho^{-1}
$$

Six bar-specimens of each composite material were tested and six repeated measurements of the volume resistivity were done for each of them by the four-point-probe method at different lo- cations on each specimen. The results were used to calculate an average value. The average resistivity was then converted to average conductivity [15]

\subsubsection{Shear viscosity}

Melt rheological properties were obtained with an ARES oscillatory rheometer (Rheometric Scientific Co.) at $190^{\circ} \mathrm{C}$ in nitrogen, using a plate-plate geometry with a plate diameter of 25 $\mathrm{mm}$. The determination of rheological characteristics of all samples was performed by applying polymer-sheet samples with a thickness of about $2 \mathrm{~mm}$. Frequency sweeps were performed between 0.1 and $100 \mathrm{rad} / \mathrm{s}$ at strains within the linear viscoelastic range. Repeat sweeps with increasing and decreasing frequency were performed in order to check the sample over time. Shear viscosity was measured in triplicate, and the results were used to calculate an average for all the composite samples.

\subsubsection{Raman spectroscopy}

FT-Raman measurements were performed using an RFS1000/s (Bruker, Germany). Laser light of $1064 \mathrm{~nm}$ from a NdYAG laser was used for excitation. A power density of about 0.5 $\mathrm{mW} / \mathrm{cm}^{2}$ was used to avoid blackbody radiation arising from the black CNTs.

\section{Results and Discussion}

\subsection{Morphology of MWCNTs}

Field emission-SEM images of as-received MWCNTs, acid treated MWCNTs and mechanofused MWCNTs are show in Fig. 2. As shown in the SEM images, the as-received MWCNTs are highly entangled and densely attached each other. However, the acid treated MWCNTs and mechanofused MWCNTs are less entangled and more separate (Fig. 2b). The acid-treatments are known to shorten the length of the MWCNTs and to introduce hydroxyl functional groups to the MWCNT walls. The nanotubes are not coiled but generally curved. The length of the nanotubes was difficult to determine definitively due to the entangled arrangement, but are at least on the order of microns. Furthermore, on comparing Fig. 2a with Fig. 2c, it was found that the typical agglomerate size had decreased from several tens to a few microns after the mechanofusion process. The surface morphology of the mechanofused MWCNTs seems not as loose as that of the asreceived MWCNTs. The mechanofused MWCNTs exhibit a significant decrease of agglomeration. This indicates that the outer surfaces of the nanotubes were partially cut and destructed during the mechanofusion process. To supporting this observation, Raman spectroscopy measurement was carried out.

SEM images of the results from conventional dry mixing and the mechanofusion process are shown in Fig. 3. As seen in Fig. 3a, after conventional dry mixing of MWCNT and PP particles, only a little of the MWCNT adhered onto the PP particles. In Figs. 3bd, the MWCNT coated the PP particles efficiently. In other words, mechanofusion was a suitable method to make hybrid-PP particles coated with MWCNTs. It was also found that MWCNTs could be shortened efficiently by the mechanofusion technique. The addition of PP could increase the cutting efficiency and shorten the lengths of the MWCNTs. The cutting mechanism in the above-mentioned 


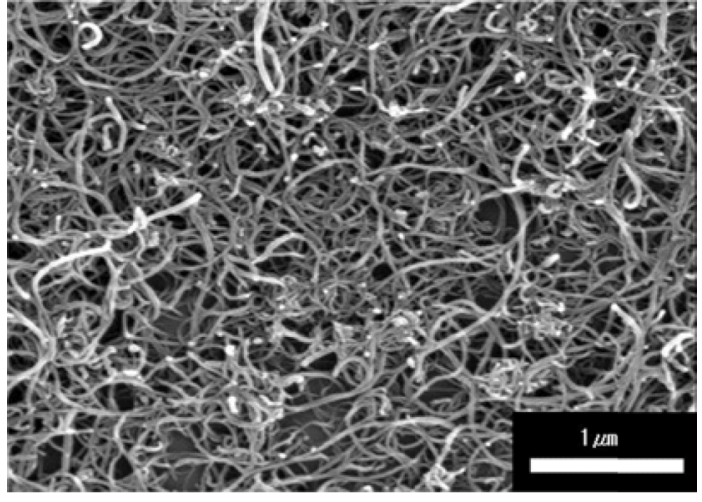

(a)

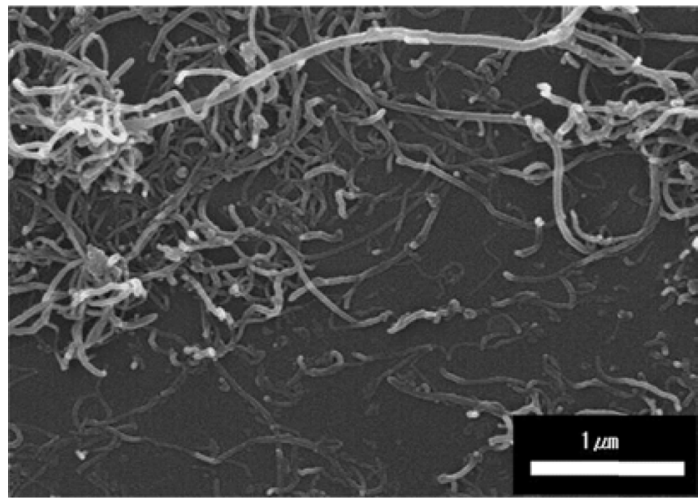

(b)

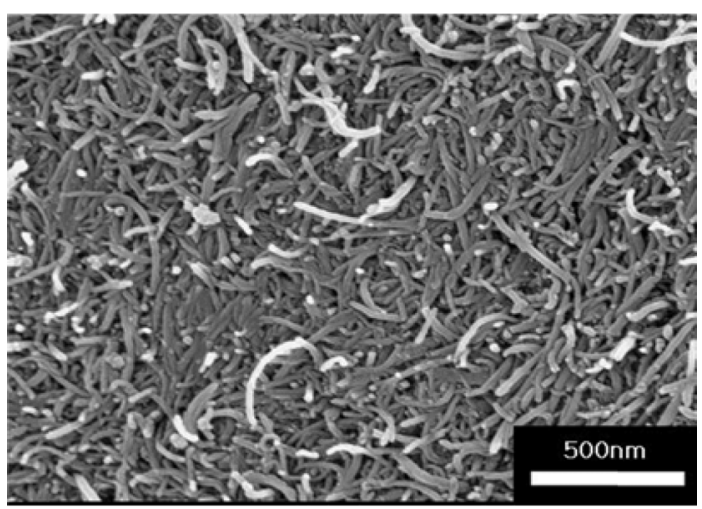

(c)

Fig. 2. Scanning electron microscopy images of multi-walled carbon nanotube: (a) as-received, (b) acid-treated, (c) mechanofused.

process is thought to be as follows: the mechanical forces, such as the shear force and compression force coming from the arm head and rotating chamber revolving face-to-face at high speeds, played the key role in the direct cutting of MWCNTs and embedding the MWCNT in the polymer matrix.

The Raman spectra in Fig. 4 show two major peaks in the high frequency range: the tangential mode or so-called graphite or " $\mathrm{G}$ " band at $1585 \mathrm{~cm}^{-1}$ and the "D" band assigned to carbonaceous compounds or defects in nanotubes at $1353 \mathrm{~cm}^{-1}$ [9]. The intensity-ratio of D-band over G-band in the mechanofused

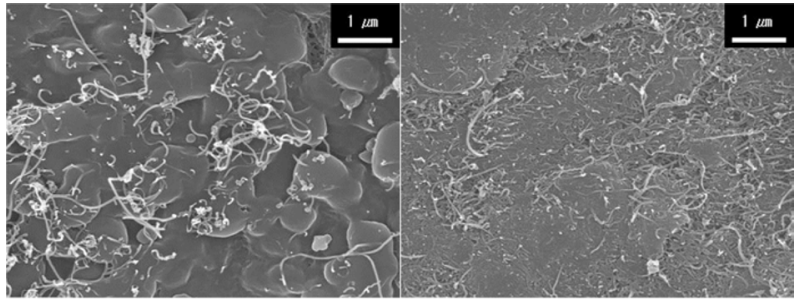

(a)

(b)

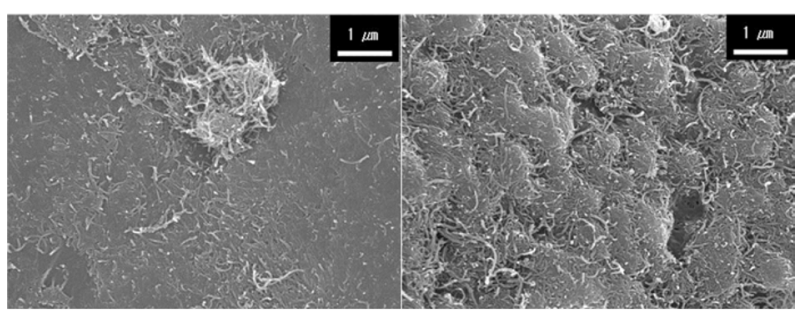

(c)

(d)

Fig. 3. Scanning electron microscopy images of the multi-walled carbon nanotube (MWCNT)-polypropylene (PP) particles: (a) conventional dry mixing, (b) MWCNT-mechanofused-PP (2 wt\%), (c) MWCNT-mechanofused-PP (5 wt\%), (d) MWCNT-mechanofused-PP (15 wt\%).

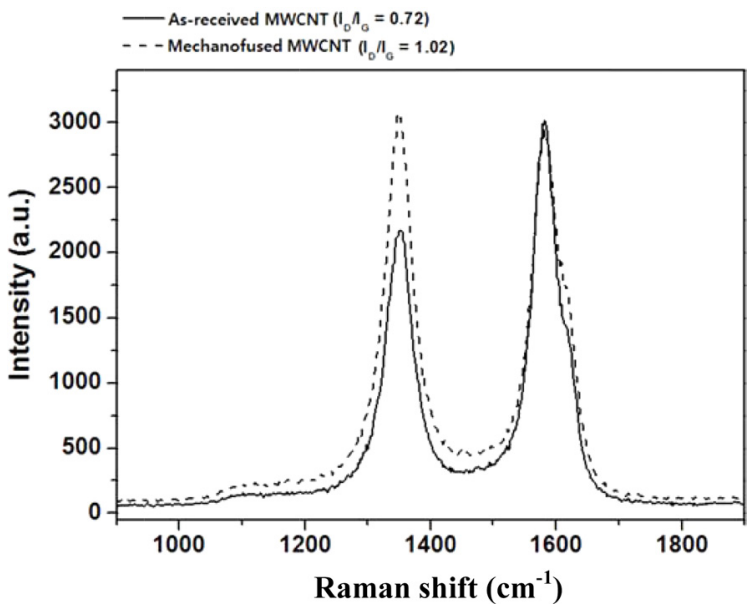

Fig. 4. FT-Raman spectra of multi-walled carbon nanotube (MWCNT).

MWCNTs was higher than that for acid-treated MWCNTs and as-received MWCNTs. This observation indicated that the extent of defects of the acid-treated MWCNTs was less than that of the mechanofused MWCNTs.

Dispersion of the MWCNTs in the composite was examined using OM, as shown in Fig. 5. We obtained short MWCNTs from a homogeneous and stable dispersion. Highly entangled clusters and segregated-phase nanotubes are shown on the surface of the composite formed by conventional dry mixing Fig. 5a; whereas, the mechanofused MWCNTs were uniformly dispersed and able to make a three-dimensional conductive network, as seen in Fig. $5 \mathrm{~b}$. Based on these findings, it can be said that disentanglement of the MWCNTs is effectively obtained by using the mechanofusion process. 


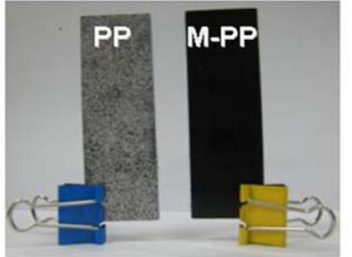

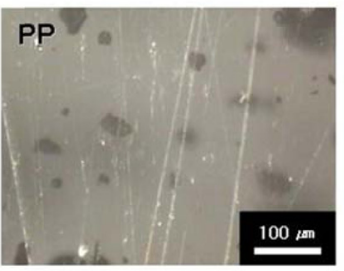

(a)

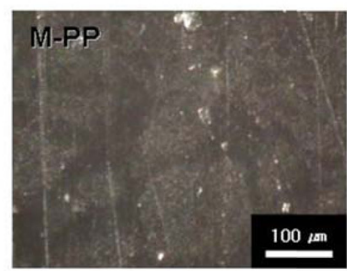

(b)
Fig. 5. Optical microscopy of multi-walled carbon nanotube/polypropylene composite (1 wt\%): (a) conventional dry mixing, (b) mechanofusion process.

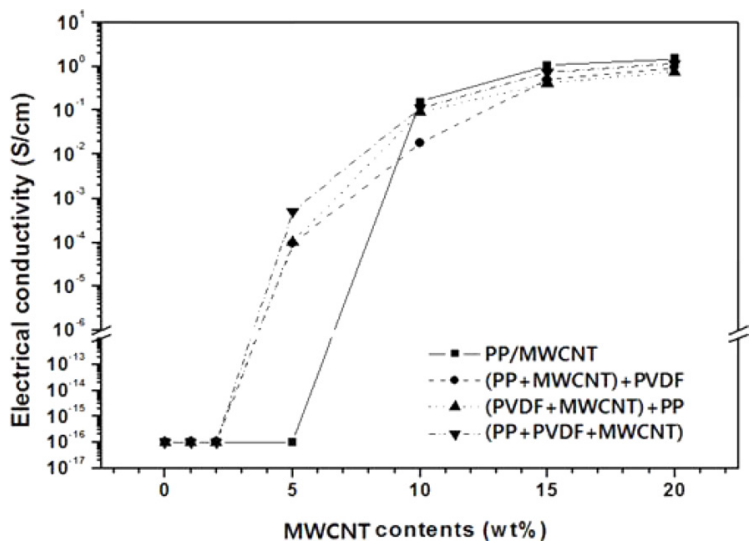

Fig. 6. Electrical conductivity of PP-PVDF-MWCNT blends. PP: polypropylene, PVDF: poly(vinylidene fluoride), MWCNT: multi-walled carbon nanotube.

\subsection{Electrical conductivity and morphology of the immiscible polymer blends}

\subsubsection{Electrical conductivity of the PP-PVDF-MWCNT} blends

The aim of mixing PVDF with an MWCNT-filled PP material was to form a co-continuous phase structure between both polymeric components such that the filled PP formed a continuous phase, acting as an electrical pathway throughout the same volume. In addition, the influence of the blending procedure on the electrical properties of the blends was investigated using three modes of incorporation: (PP+PVDF+MWCNT), $(\mathrm{PP}+\mathrm{MWCNT})+\mathrm{PVDF}$, and $(\mathrm{PVDF}+\mathrm{MWCNT})+\mathrm{PP}$. These composites were prepared under the same conditions as their blend. The electrical conductivity of the composites was a function of the weight fraction of MWCNTs. The electrical conductivity of different compositions of PP-PVDF blends for various modes of MWCNT incorporation are shown Fig. 6. The electrical conductivity of the resulting composites was almost the same

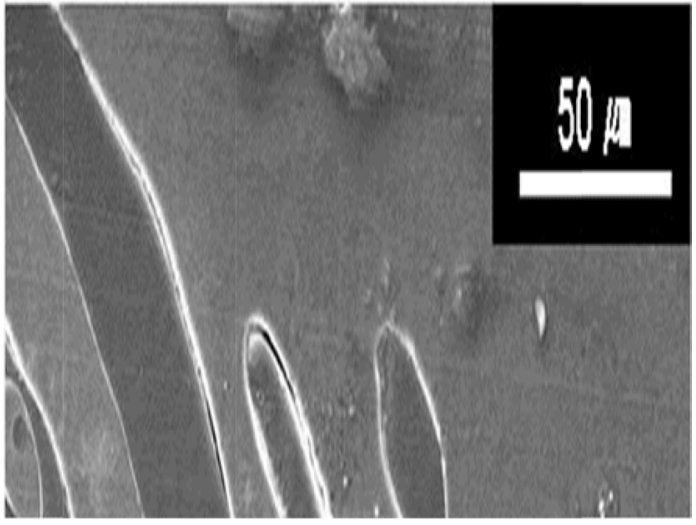

(a)

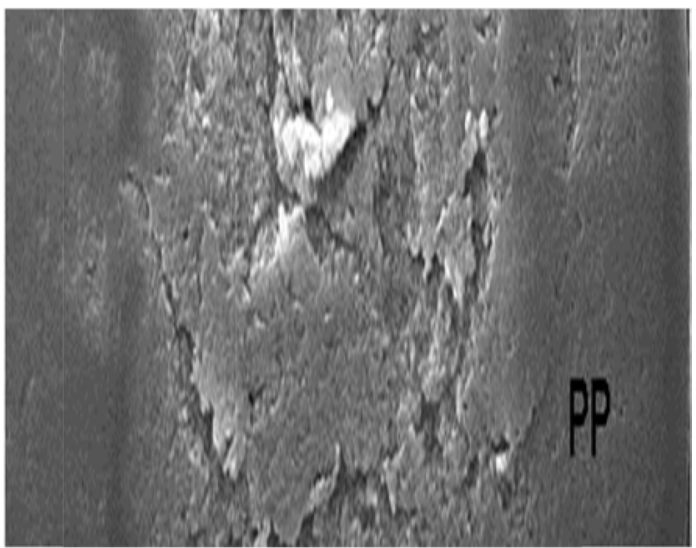

(b)

Fig. 7. Scanning electron microscopey images of microtome section of (a) PP-PVDF-MWCNT blend, (b) MWCNT selective localized at PP phase in PP-PVDF-MWCNT blend. PP: polypropylene, PVDF: poly(vinylidene fluoride), MWCNT: multi-walled carbon nanotube.

for all three modes of incorporation. At low MWCNT loadings, the electrical conductivity remained similar to that of the pure PP. Between 2 and $5 \mathrm{wt} \%$, the conductivity took a sizeable step of 8-10 orders of magnitude, a percolation threshold around 5 $\mathrm{wt} \%$. After that, increase in the conductivity with further increase in the MWCNT concentration slowed. The melt-mixing procedure and polymer ratio, as well as the MWCNT loading and susceptibility; affect the phase morphology and preferential MWCNT location, which determine the blend resistivity level. When the PP content was sufficient to allow for the formation of sufficiently dispersed PP particles with MWCNT located in their phase, conductivity was enhanced.

\subsubsection{Morphology of the PP-PVDF-MWCNT blends}

Figs. 7a and $\mathrm{b}$ show SEM images of microtome sections of the MWCNT-filled PP-PVDF blend containing $10 \mathrm{wt} \% \mathrm{MW}$ CNT. It is very clear that a two-phase structure is present and that MWCNT is only localized in the PP phase. The compression molding of polymers is a processing technique which is conducted in the absence of shear stress so that the opportunity for the MWCNT to penetrate the viscous polymer phases is severely restricted. The MWCNTs are then expected to remain localized 


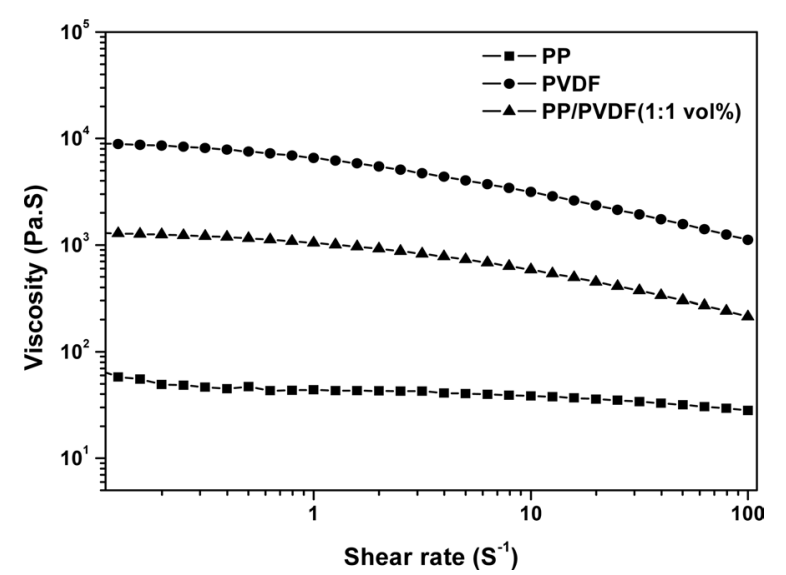

Fig. 8. Shear viscosity versus shear rate of molten polypropylene (PP), poly(vinylidene fluoride) (PVDF), PP/PVDF (1:1 vol\%) blend at $180^{\circ} \mathrm{C}$.

at the frontier of the original polymer grains and thus to percolate along this specific boundary, depending on the ternary blend composition and fineness of dispersion. The MWCNTs are thermodynamically driven to this PP phase. The conductive fillers observed to accumulate in the one-polymer-phase depend on the rheology of the polymer blend under the processing conditions. The formation of co-continuous structures in melt-mixed blends primarily depend on the viscosity and elasticity ratios between the blend components, under the mixing conditions; whereas the interfacial tension is mainly related to the stability of the morphology. To achieve continuity of the PP, the PP phase should have a melt viscosity lower than that of PVDF under the given mixing conditions. The viscosity curves of the PP, PVDF and PP-PVDF blends are shown Fig. 8 at $180^{\circ} \mathrm{C}$. The higher melt viscosity of the PP-PVDF blend, at very low oscillation frequencies relative to its constituting components, is already indicative of the formation of a co-continuous structure.

\subsection{Electrical conductivity and morphology of MWCNT-filled PP-composite formed using the mechanofusion technique}

3.3.1. Electrical conductivity of the MWCNT-PP composite

The electrical conductivities of MWCNT-filled PP composites were measured by the four-probe method. A significant difference between conventional mixing and the mechanofusion process was observed in their electrical conductivity. Fig. 9 shows the conductivity of polymer composites at different loadings of MWCNT. Polymer composites made with different processing methods, with the same MWCNT loading, showed different conductivity, which was related to the morphology of the MWCNT in the polymer matrix. It was noticeable that even though all the polymer composites had the same MWCNT content $(5 \mathrm{wt} \%)$, the PP-composites displayed different conductivity. As seen Fig. 9, the percolation threshold for conventional dry mixing clearly occurs around $5-10 \mathrm{wt} \%$ of MWCNT. In contrast, the percolation of composites prepared by the mechanofusion process occurred around 2-5 wt $\%$ of MWCNT. The percolation threshold of the PP-MWCNT composites were successfully lowered using the mechanofusion process. However, the electri-

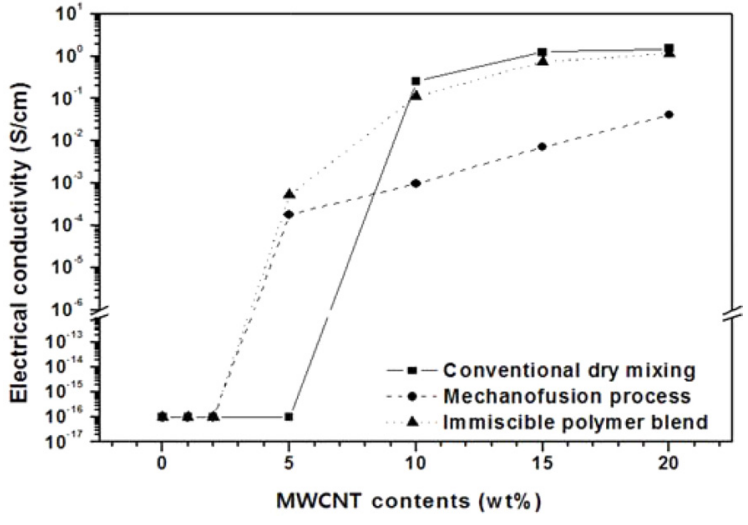

Fig. 9. Electrical conductivity of multi-walled carbon nanotube (MWCNT)-filled polypropylene composites.

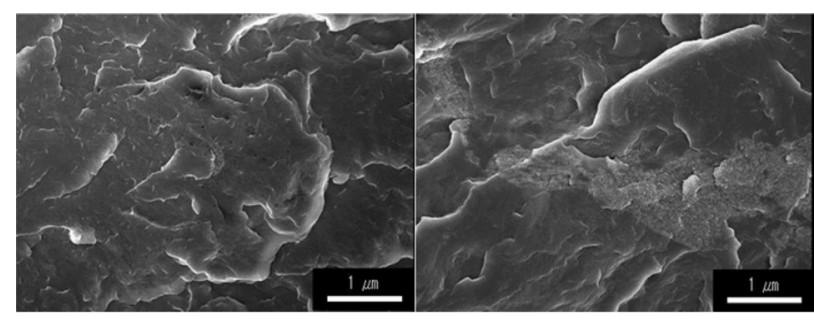

(a)

(b)

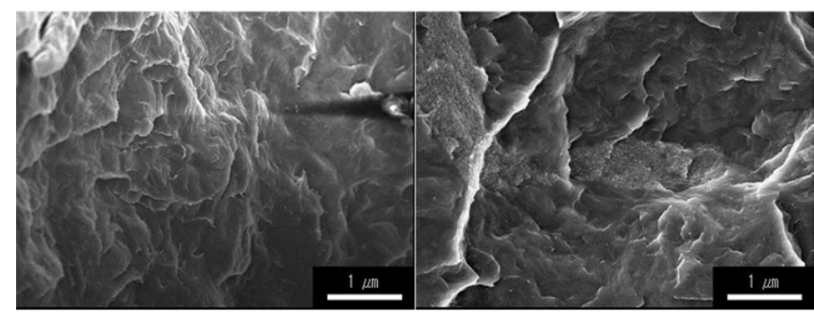

(c)

(d)

Fig. 10. Scanning electron microscopy images of the cryofracture surface of multi-walled carbon nanotube/polypropylene composites: (a) conventional dry mixing (2 wt\%), (b) mechanofusion process (2 wt\%), (c) conventional dry mixing (5 wt\%), (d) mechanofusion process (5 wt\%).

cal conductivity of the MWCNT-mechanofused-PP-composite is lower than that of the composite prepared by conventional dry mixing. Because the structural defects of the MWCNTs were slightly increased using mechanofusion, this lead to lower electrical conductivity.

Assuming a 1000 aspect ratio, theoretical calculations for cylindrically-shaped fillers predicted that the onset of percolation of polymer-MWCNT composites would begin at $\sim 0.05$ vol $\%$ filler concentration. Experimentally, percolation concentrations as low as $0.04 \mathrm{wt} \%$ for epoxy-MWCNT composites and $0.05 \mathrm{wt} \%$ for PP-MWCNT film [9] have been reported along with percolation behavior in the range of $1-5$ vol\% MWCNT for most of the polymer-MWCNT composites. In fact, most polymer-MWCNT composites have been prepared by solventassisted processes such as solution mixing or in-situ polym- 
erization in solvent, to alleviate the interfacial repulsive force between MWCNT and the polymer matrix. In terms of mixing efficiency, the solvent-assisted process is superior to melt mixing, since there is a large discrepancy in viscosity between MWCNT-nanotubes and polymer melt as well as a lack of interfacial mediation between the two immiscible phases. It is inevitable that better dispersion of the MWCNT in solution, resulted in lower percolation concentration and conductivity. On other hand, the mechanofusion process has advantages of simplicity (needs no solvent), environmental friendliness and continuity that are applicable to conventional systems. Although not the lowest value reported [16], the percolation threshold of $\sim 3 \mathrm{wt} \%$ MWCNT (using the melt-mixing process) in our study is appreciated to present electrical performance suitable to applications such as electrostatic dissipation, electrostatic printing and EMI shielding [17]. In the light of these facts, our preliminary work is thought to reveal the great potential of this mechanofusion technique for mass production of polymer-MWCNT composites for industrial applications.

\subsubsection{Morphology of MWCNT-PP composite}

Fig. 10 shows scanning electron micrographs of the cryofracture surface of the MWCNT-filled PP-composites containing 2 and $5 \mathrm{wt} \%$, respectively. It is noted that there are conductive pathways in the MWCNT-PP composite in Figs. 10b and d. MWCNTs are forced into conductive pathways at low concentration because of their inability to occupy volume already filled by the much larger polymer particles. There appears to be good qualitative agreement between our experimental findings and current models dealing with segregated microstructure. The difference in morphology of the MWCNT-PP composite results from the segregated microstructure induced by the composite during the mechanofusion process. With the morphological features described in Fig. 10, it can be concluded that the mechanofusion technique was for more effective than the conventional dry-mixing method in improving electrical and dialectical properties of composites prepared by the melt-mixing process. The cause was that the mechanofused MWCNT enhanced the formation of the electrical-network structure, and was dispersed more uniformly in the polymer matrix than for conventional dry mixing of MWCNT. As a result, mechanofusion lead to a lowered percolation threshold as conductive pathways were formed at lower filler concentrations.

\section{Conclusions}

The critical amount of electrically-conductive filler necessary to build up a continuous conductive network, and accordingly, to make the material conductive is referred to as the percolation threshold. In this study, we focused two different approaches (immiscible polymer blending and a mechanofusion technique) on achieving a low percolation threshold in conductive MWCNT-polymer composites. Moreover, we investigated the effects of different processing methods on the morphological development and percolation threshold of the resulting composites.

The percolation threshold was reduced by using an immiscible polymer blend (PP-PVDF 1:1 vol\%). This may be due to the formation of a co-continuous network structure. When binary blends are considered, the percolation threshold depends strongly on the phase morphology and distribution of MWCNT in the polymer blend. The immiscible polymer blends were intended to form a co-continuous structure. The MWCNT selectively localized the continuous PP phase such that the MWCNT-filled PPphase acted as an electrical pathway through the blends.

The percolation threshold of the MWCNT-filled PP-composites can be dramatically reduced by using this polymer blend system and mechanofusion technique. Mechanofusion was found to enhance the formation of the MWCNT-network structure and lead to more uniform dispersion. As a result, the percolation threshold of PP-MWCNT composites were successfully lowered using mechanofusion and immiscible polymer blends.

\section{Acknowledgements}

This work was financially supported by the Soft Innovative Materials Research Center of the Korea Institute of Science and Technology (KIST). This research was also kindly supported by a grant from the Fundamental R\&D Program for Technology of World Premier Materials, funded by the Ministry of Knowledge Economy, Republic of Korea.

\section{References}

[1] Feng J, Chan CM. Carbon black-filled immiscible blends of poly(vinylidene fluoride) and high density polyethylene: electrical properties and morphology. Polym Eng Sci, 38, 1649 (1998) http://dx.doi.org/10.1002/pen.10335.

[2] Pötschke P, Bhattacharyya AR, Janke A. Morphology and electrical resistivity of melt mixed blends of polyethylene and carbon nanotube filled polycarbonate. Polymer, 44, 8061 (2003). http:// dx.doi.org/10.1016/j.polymer.2003.10.003.

[3] Wu M, Shaw LL. On the improved properties of injection-molded, carbon nanotube-filled PET/PVDF blends. J Power Sources, 136, 37 (2004). http://dx.doi.org/10.1016/j.jpowsour.2004.04.016.

[4] Wu M, Shaw L. Electrical and mechanical behaviors of carbon nanotube-filled polymer blends. J Appl Polym Sci, 99, 477 (2006). http://dx.doi.org/10.1002/app.22255.

[5] Xu HP, Dang ZM, Yao SH, Jiang MJ, Wang D. Exploration of unusual electrical properties in carbon black/binary-polymer nanocomposites. Appl Phys Lett, 90, 152912 (2007). http://dx.doi. org/10.1063/1.2723644.

[6] Han JH. Current Status on Synthesis of Carbon Nanotubes and Their Applications to Conducting Polymer. Polymer Science and Technology, 16, 162 (2005).

[7] Yi XS, Wu G, Ma D. Property balancing for polyethylene-based carbon black-filled conductive composites. J Appl Polym Sci, 67, 131 (1998). http://dx.doi.org/10.1002/(SICI)1097-4628(19980103) 67:1<131::AID-APP15>3.0.CO;2-4.

[8] Leclère P, Lazzaroni R, Gubbels F, Calberg F, Dubois P, Jérôme R, Brédas JL. Carbon black-filled polymer blends: a scanning probe microscopy characterization. MRS Online Proc Lib, 457, 475 (1996). http://dx.doi.org/10.1557/PROC-457-475.

[9] Andrews R, Jacques D, Minot M, Rantell T. Fabrication of carbon multiwall nanotube/polymer composites by shear mixing. macromolecular materials and engineering, 287, 395 (2002). 
http://dx.doi.org/10.1002/1439-2054(20020601)287:6<395::AIDMAME395>3.0.CO;2-S.

[10] Ajayan PM, Stephan O, Colliex C, Trauth D. Aligned carbon nanotube arrays formed by cutting a polymer resin--nanotube composite. Science, 265, 1212 (1994). http://dx.doi.org/10.1126/ science.265.5176.1212.

[11] Calvert P. Nanotube composites: a recipe for strength. Nature, 399, 210 (1999). http://dx.doi.org/10.1038/20326.

[12] Smuckler JH, Finnerty PM. Performance of conductive carbon blacks in a typical plastics system. Adv Chem Ser, 134, 171 (1974). http://dx.doi.org/10.1021/ba-1974-0134.ch017.

[13] Verhelst WF, Wolthuis KG, Voet A, Ehrburger P, Donnet JB. The role of morphology and structure of carbon blacks in the electrical conductance of vulcanizates. Rubber Chem Technol, 50, 735
(1977). http://dx.doi.org/10.5254/1.3535171.

[14] Gubbels F, Jerome R, Teyssie P, Vanlathem E, Deltour R, Calderone A, Parente V, Bredas JL. Selective localization of carbon black in immiscible polymer blends: a useful tool to design electrical conductive composites. Macromolecules, 27, 1972 (1994). http://dx.doi.org/10.1021/ma00085a049.

[15] Runyan WR. Semiconductor Measurements and Instrumentation, McGraw-Hill, New York, NY (1975)

[16] Masci G, Aulenta F, Crescenzi V. Uniform-sized clenbuterol molecularly imprinted polymers prepared with methacrylic acid or acrylamide as an interacting monomer. J Appl Polym Sci, 83, 2660 (2002). http://dx.doi.org/10.1002/app.10232.

[17] Miller B. Intumescents, FR efficiency pace flame retardant gains. Plastics World, 54, 73 (1996). 